\title{
P130: Assessment of hand hygiene practices at the two children's hospitals in Greece
}

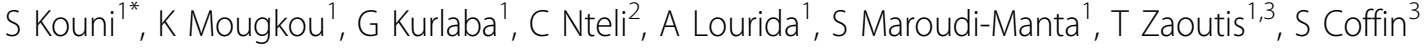 \\ From 2nd International Conference on Prevention and Infection Control (ICPIC 2013) \\ Geneva, Switzerland. 25-28 June 2013
}

\section{Introduction}

Hand hygiene $(\mathrm{HH})$ is one of the basic components of the infection control program and is frequently considered synonymous with hand washing. The use of a waterless, alcohol-based hand rub (ABHR) is more effective, saves time and promote better compliance than hand washing.

\section{Objectives}

The aim of the study was to estimate the current $\mathrm{HH}$ practices in order to schedule the future interventions.

\section{Methods}

Observational $\mathrm{HH}$ data were collected from 13 wards in 2 pediatric hospitals in Athens, including medical/surgical, oncology/transplant (BMTU), and intensive care units (ICUs), during 65, 1-hour observations periods, from October 2012 to January 2013. HH opportunities and attempts were designated as appropriate or inappropriate per WHO criteria.

\section{Results}

A total of $1271 \mathrm{HH}$ opportunities were identified during the observation period. Overall $\mathrm{HH}$ compliance was 33\% $(417 / 1271)$ of which $58.8 \%$ were appropriate. Compliance differed by role: nurses (49\%), physicians $(24 \%)$ and others $(19 \%)(\mathrm{p} \leq 0.001)$. Healthcare workers $(\mathrm{HCWs})$ and visitors were more likely to use soap and water (76.1\%) compared to ABHR (23.9\%) and no significant difference was detected among these groups $(\mathrm{p}=0.330)$. In regards to type of department, the use of ABHR was found to be strongly higher in Surgical wards (71.8\%) compared to the rest of wards which this rate ranges from $11.1 \%$ in NICUs to $33.3 \%$ in emergency departments $(\mathrm{p}<0.001)$. The $\mathrm{HH}$ procedure was appropriate in $63.4 \%$ and $45.4 \%$ among those used soap and water and ABHR, respectively $(\mathrm{p}=0.002)$. The most commonly identified $\mathrm{HH}$ opportunities were after child contact (381), before child contact (376), after contact with child's surroundings (358) and before aseptic procedure (95). Despite the fact that all HCWs use more often hand washing, a minor number of $\mathrm{HH}$ opportunities (61) were identified after contact with body fluids, the step of $\mathrm{HH}$ which demands this $\mathrm{HH}$ method.

\section{Conclusion}

A low level of $\mathrm{HH}$ compliance and use of ABHR was observed. The education of the appropriate use of ABHR must be the main intervention for hand hygiene in these health care facilities.

\section{Disclosure of interest}

None declared.

\section{Author details}

'The Stavros Niarchos Foundation-Collaborative Center for Clinical Epidemiology and Outcomes Research (CLEO), University School of Medicine, Athens, Greece. ${ }^{2}$ Pediatric Intensive Care Unit, Aglaia Kyriakou Children's Hospital, Athens, Greece. ${ }^{3}$ Division of Infectious Diseases, Department of Pediatrics, UPENN School of Medicine, Philadelphia, PA, USA.

Published: 20 June 2013

doi:10.1186/2047-2994-2-S1-P130

Cite this article as: Kouni et al:: P130: Assessment of hand hygiene practices at the two children's hospitals in Greece. Antimicrobial Resistance and Infection Control 2013 2(Suppl 1):P130.

'The Stavros Niarchos Foundation-Collaborative Center for Clinical Epidemiology and Outcomes Research (CLEO), University School of Medicine, Athens, Greece

Full list of author information is available at the end of the article

(c) 2013 Kouni et al; licensee BioMed Central Ltd. This is an Open Access article distributed under the terms of the Creative Commons 